\title{
The Protective Effect of Lavender Essential Oil and Its Main Component Linalool against the Cognitive Deficits Induced by D-Galactose and Aluminum Trichloride in Mice
}

\author{
Pan Xu, ${ }^{1}$ Kezhu Wang, ${ }^{1}$ Cong Lu, ${ }^{1}$ Liming Dong, ${ }^{1}$ Li Gao, ${ }^{2}$ Ming Yan, ${ }^{2}$ Silafu Aibai, \\ Yanyan Yang, ${ }^{3}$ and Xinmin Liu ${ }^{1}$ \\ ${ }^{1}$ Research Center of Pharmacology and Toxicology, Institute of Medicinal Plant Development (IMPLAD), \\ Chinese Academy of Medical Sciences and Peking Union Medical College, Beijing 100193, China \\ ${ }^{2}$ Department of Pharmacology and Toxicology Laboratory, Xinjiang Institute of Traditional Uighur Medicine, \\ Urumqi, Xinjiang 830049, China \\ ${ }^{3}$ China Astronauts Research and Training Center, Beijing 100094, China \\ Correspondence should be addressed to Xinmin Liu; liuxinmin@hotmail.com
}

Received 6 November 2016; Revised 26 January 2017; Accepted 13 February 2017; Published 26 April 2017

Academic Editor: Tadaaki Satou

Copyright ( 2017 Pan Xu et al. This is an open access article distributed under the Creative Commons Attribution License, which permits unrestricted use, distribution, and reproduction in any medium, provided the original work is properly cited.

\begin{abstract}
Lavender essential oil (LO) is a traditional medicine used for the treatment of Alzheimer's disease (AD). It was extracted from Lavandula angustifolia Mill. This study was designed to investigate the effects of lavender essential oil (LO) and its active component, linalool (LI), against cognitive impairment induced by $\mathrm{D}$-galactose (D-gal) and $\mathrm{AlCl}_{3}$ in mice and to explore the related mechanisms. Our results revealed that LO $(100 \mathrm{mg} / \mathrm{kg})$ or LI $(100 \mathrm{mg} / \mathrm{kg})$ significantly protected the cognitive impairments as assessed by the Morris water maze test and step-though test. The mechanisms study demonstrated that LO and LI significantly protected the decreased activity of superoxide dismutase (SOD), glutathione peroxidase (GPX), and protected the increased activity of acetylcholinesterase (AChE) and content of malondialdehyde (MDA). Besides, they protected the suppressed nuclear factorerythroid 2-related factor 2 (Nrf2) and heme oxygenase-1 (HO-1) expression significantly. Moreover, the decreased expression of synapse plasticity-related proteins, calcium-calmodulin-dependent protein kinase II (CaMKII), p-CaMKII, brain-derived neurotrophic factor (BDNF), and TrkB in the hippocampus were increased with drug treatment. In conclusion, $\mathrm{LO}$ and its active component LI have protected the oxidative stress, activity of cholinergic function and expression of proteins of Nrf2/HO-1 pathway, and synaptic plasticity. It suggest that LO, especially LI, could be a potential agent for improving cognitive impairment in AD.
\end{abstract}

\section{Introduction}

Alzheimer's disease (AD) is an age related neurodegenerative disease of the brain that is the most common cause of dementia in the world. The disease is characterized by a progressive deterioration of cognitive functions [1]. Learning and memory process is linked with the induction of long-time potential, which is interpreted as the retention of information. LTP could ensure long-term changes in synaptic efficacy in distributed networks, leading to persistent changes in the behavioral patterns, actions, and choices [2]. The hippocampus is necessary for LTP, in which the changed level of synaptic protein, neural substrates, and neurotransmitters in $\mathrm{AD}$ might directly lead to the loss of memory formation, storage, or retrieval [3]. The cognitive damage interferes with the normal life of patients and places a considerable burden on society. Recent studies showed that combined administration of chronic D-gal and $\mathrm{AlCl}_{3}$ has induced obvious cognitive impairments [4-6]. Even before the cognitive changes appear, the pathological changes, including abnormal cholinergic system, mitochondrial dysfunction, apoptosis, amyloid- $\beta$ peptide $(\mathrm{A} \beta)$ deposition, and especially obvious oxidative stress, were observed in the model [6-9]. It suggested that the $\mathrm{D}$-gal and $\mathrm{AlCl}_{3}$ induced model is a useful model for the drugs screening in AD.

Though the exact mechanism of $\mathrm{AD}$ remains unclear, now oxidative stress has been proposed to be a critical factor in the course of $\mathrm{AD}[10]$. The imbalance between the production 
of reactive oxygen species (ROS) and antioxidant defense systems could cause oxidation of biological macromolecules, aggravating mitochondrial dysfunction and ultimately leading to cell death or neurodegeneration [11]. The hippocampus is vulnerable to that oxidative damage [12]. There are many endogenous antioxidant enzymes and heme oxygenase-1 (HO-1) is one of the most effective [13]. Pharmacological induction of HO-1 could give an adaptive survival response against oxidative insults [14]. Nuclear factor-erythroid 2related factor 2 (Nrf2) is an upstream transcription factor, regulating HO-1 expression [15]. Thus, antioxidant therapy, especially those based on Nrf-2 and HO-1 targets, might play an important role in the prevention and treatment of AD.

Lavender, which is used for therapeutic and cosmetic, belongs to the family Labiatae (Lamiaceae) and species Lavandula angustifolia Mill.. Traditionally, Lavender has been used to treat anxiety, insomnia, depression, convulsion, pain, and cerebrovascular diseases in many countries [16]. Lavender essential oil (LO), isolated from Lavandula plants, is the most common used form of lavender. $\mathrm{LO}$ was reported to possess various biological activities in central nervous system and show effectiveness in the management of depression, anxiety, stress, and cerebral ischemia [17-20]. Recent studies found that LO has neuroprotective and cognitive improvement effects in some AD models though antioxidant properties [21, 22]. (-)-Linalool (LI), as the major component of LO (40\%), is also responsible for its therapeutic properties [23]. LI has antioxidant, anti-inflammatory, antitumor, antidepressant, and antimicrobial activities. Increasing evidences demonstrated that the antioxidant activity of LI could protect neurons from neurotoxicity and damage. Moreover, LI protected neuropathological and behavioral impairments in old triple transgenic AD mice [24].

Though there were some previous studies about the potential protective effect of LO or LI on the cognitive and pathological impairments in $\mathrm{AD}$ models, their pharmacological study in $\mathrm{D}$-gal and $\mathrm{AlCl}_{3}$ induced mice, an excellent $\mathrm{AD}$ model, was seldom reported and the related mechanism research was limited. Therefore, the present study investigated the effects of LO and LI on cognitive deficits induced by D-gal and $\mathrm{AlCl}_{3}$ in mice using Morris water maze and step-though tests. Meantime, the changes of oxidative stress in mice were also analyzed. Additionally, we detected Nrf2, HO-1, calcium-calmodulin-dependent protein kinase II (CaMKII), p-CaMKII, BDNF, TrkB expression, and AChE activity to explore the possible action mechanisms of LO and LI.

\section{Materials and Methods}

2.1. Drugs and Materials. The lavender essential oil (LO) was provided by Yili Brother Biotech, Inc (Xinjiang, China). LO is extracted by steam distillation from Lavandula angustifolia grown in Xinjiang and harvested in August 2015. Linalool (LI, Figure 1) with a purity of $98.5 \%$ determined by HPLC was obtained from the National institutes for Food and Drug Control (ID: 4BJH-UDPM, Beijing, China). D-galactose (D-gal) and aluminum trichloride $\left(\mathrm{AlCl}_{3}\right)$ were purchased from (Amresco Company, Solon, OH, USA). Assay kits of superoxide dismutase (SOD), glutathione peroxidase (GPX),

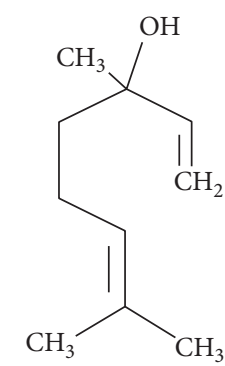

FIGURE 1: Molecular structure of linalool.

malondialdehyde (MDA), and acetylcholinesterase (AChE) were purchased from Nanjing Jiancheng Biotechnology Institute (Nanjing, China). Rabbit antibodies to HO-1 and Nrf2 (1:1000, Abcam, USA) were form Abcam (Cambridge, MA, USA) and rabbit antibodies to CaMKII, p-CaMKII, BDNF, TrkB, $\beta$-actin, and Horseradish peroxidase- (HRP-) conjugated goat anti-rabbit IgG secondary antibodies were from Cell Signaling Technology (Boston, MA, USA). Protein extraction kit and BCA protein assay kit and ECL kit were from Cwbio (Beijing, China).

2.2. Lavender Oil Chromatographic Analysis. The chemical composition of LO was confirmed and analyzed using Gas Chromatography-Mass Spectrometer (GC-MS, Thermo Fisher Trace 1310/ISQ Mass Selective detector), with a column of Agilent HP-5MS capillary column $(30 \mathrm{~m} \times 0.25 \mathrm{~mm} \times$ $0.25 \mu \mathrm{m}$ ). The sample was injected by splitting (split ratio, $1: 100)$. The oven temperature was programed as follows: $50^{\circ} \mathrm{C}, 1 \mathrm{~min} ; 2^{\circ} \mathrm{C} / \mathrm{min}$ to $100^{\circ} \mathrm{C}$ for $5 \mathrm{~min} ; 2^{\circ} \mathrm{C} / \mathrm{min}$ to $240^{\circ} \mathrm{C}$ for $5 \mathrm{~min}$. The injector and detector temperatures were $250^{\circ} \mathrm{C}$ and $280^{\circ} \mathrm{C}$, respectively. Carrier gas was helium at a flow rate of $1 \mathrm{~mL} / \mathrm{min}$. Mass range was $20-400 \mathrm{~m} / z$. The volatile compounds were identified by comparing their retention indices (RI) or mass spectra with those of reference substances, NIST/NBS libraries and literature data. Relative abundances of the components were derived by using the same instrumentation with the flame ionization detector (FID) configuration. Data extraction and analysis were performed using the Thermo Xcalibur software. The constituents were expressed as percentages from peak area normalization, assuming that the total injection was $100 \%$ of essential oil.

2.3. Animals and Drug Administration. A total of 90 male C57BL/6J mice (12 weeks) were purchased from the Vital River Laboratories (Qualified No.: SCXK 2012-0001, Beijing, China). They were housed under temperature controlled condition $\left(25^{\circ} \mathrm{C}\right)$ with alternating light/dark cycle (lights, 8:00 AM-8:00 PM) and were given a standard diet and water ad libitum. Mice were allowed to acclimatize for 1 week before the beginning of the experiment. All experimental procedures were carried out under the approval and supervision of the Academy of Experimental Animal Center of the Institute of Medicinal Plant Development and in accordance with the NIH Guide for the Care and Use of Laboratory Animals.

The mice were randomly divided into 6 groups, control (given vehicle), $\mathrm{AD}$ group (given vehicle), $\mathrm{LO}+\mathrm{AD}$ groups 
$(50,100 \mathrm{mg} / \mathrm{kg} / \mathrm{d})$, and LI $+A D$ groups $(50,100 \mathrm{mg} / \mathrm{kg} / \mathrm{d})$. The $\mathrm{D}$-gal and $\mathrm{AlCl}_{3}$ were dissolved in sterile saline, while $\mathrm{LO}$ and LI were dissolved in vehicle that is a normal saline solution with $2 \%$ Tween-80 and $1 \%$ DMSO, respectively. Mice in AD and drug groups were injected intraperitoneally with $\mathrm{D}$-gal $(60 \mathrm{mg} / \mathrm{kg} / \mathrm{day})$ and $\mathrm{AlCl}_{3}(5 \mathrm{mg} / \mathrm{kg} /$ day $)$ while the control group was treated with the same volume of sterile saline for 8 weeks. Then the behavioral tests were performed. From the fifth week of modeling to the end of behavioral tests (lasted 37 days) mice were given the corresponding drug solutions of their own groups. We observed that in the fourth week of drug treatment session, the administration area in mice abdominal skin was hardened with high dose LO treatment. This phenomenon did not appear in the other groups, which might suggest the skin irritation of high dose LO.

\subsection{Behavioral Test}

2.4.1. Open-Field Test (OFT). Locomotor activity was firstly assessed to preclude its interference in cognitive function parameters [25]. The open-field computer-aided controlling system consists of four metal boxes $(30 \times 30 \mathrm{~cm}$, height $40 \mathrm{~cm}$ ) with a 120 Lux light source on the ceiling, and a video camera fixed at the top. 30 minutes after administration, each mouse was placed at the center of the tank and allowed to adapt freely for $3 \mathrm{~min}$. Then in the following $10 \mathrm{~min}$, distances travelled were recorded automatically as the index.

2.4.2. Morris Water Maze Test (MWM). The MWM test was performed to evaluate the spatial learning and memory following OFT $[26,27]$. The maze was a circular pool filled with water $\left(24-26^{\circ} \mathrm{C}\right)$ which was opaque by adding milk. The pool was divided into four equal quadrants, one of which (e.g., SE) contains a hyaline platform $(6 \mathrm{~cm}$ in diameter and $15 \mathrm{~cm}$ in height) submerged $1 \mathrm{~cm}$ below the surface. The swimming activity was recorded using a video camera overhead and analyzed via a computerized image analyzer system. In navigation experiment of 5 days containing four trial sessions per day, mice were released from one of four quadrants randomly and allowed to find the platform in $60 \mathrm{~s}$. Before and after swimming, they were left on platform for $10 \mathrm{~s}$. The escape latency and the escape rate were analyzed by a tracking and image analyzer system. Probing test was conducted with the platform removed $24 \mathrm{~h}$ after navigation. Mice were released from the quadrant (e.g., NW) opposite from the previous platform location (target quadrant) to receive $60 \mathrm{~s}$ memory retention test. The time in target quadrant and crossing number were analyzed.

2.4.3. Passive Avoidance Task (PAT). The passive avoidance test was performed one day after MWM test according to previous method [28]. The apparatus in trough-shape consisted of a white illuminated camber and a dark camber $(17 \mathrm{~cm} \times 13.5 \mathrm{~cm} \times 25 \mathrm{~cm}$, resp.). In training trial, following $180 \mathrm{~s}$ adaptation, each mouse was put into the light chamber to explore with the door opened for $300 \mathrm{~s}$. When it entered the dark chamber, a $0.5 \mathrm{~mA}$ electric foot shock $(5 \mathrm{~s})$ was delivered. $24 \mathrm{~h}$ later, the consolidation trial was performed in the same way as training. Latency to enter the dark chamber and error time were recorded in $300 \mathrm{~s}$ test session.

2.5. Brain Sample Preparation. After the last behavioral test, all mice were anesthetized and decapitated quickly. Their brains were removed immediately on ice, then the hippocampus and the cortex were dissected out and frozen in liquid nitrogen. The samples were stored at $-80^{\circ} \mathrm{C}$ for further determination.

2.6. Oxidative Parameter Assay in the Hippocampus and the Cortex. The hippocampi $(n=6)$ were weighted and sonicated with cold normal saline $(1: 10)$. Then the homogenate was centrifuged at $3,500 \mathrm{rpm} / \mathrm{min}\left(10 \mathrm{~min}, 4^{\circ} \mathrm{C}\right)$ and the supernatants were collected for assay. The SOD, GPX activities, and content of MDA were measured using commercially available assay kits according to the protocols, respectively. Briefly, the assay of SOD activity was based on its ability to inhibit the oxidation by superoxide anion free radical generated by the xanthine-xanthine oxidase system, thereby reducing the formation of water-soluble tetrazolium- (WST-) 1 formazan. The absorbance was read at $450 \mathrm{~nm}$ with a microplate reader. The GPX activity was assayed by measuring the decline of nicotinamide adenine dinucleotide phosphate reduced form (NADPH) in a coupled system at $340 \mathrm{~nm}$, which was based on it catalyzing the oxidation of reduced glutathione to oxidized glutathione. The content of MDA was assayed at $535 \mathrm{~nm}$ by monitoring thiobarbituric acid reactive substance (TBARS) formation as previously described previously [29].

2.7. Determination of Acetylcholinesterase (AChE) Activity. AChE activity in the hippocampus and cortex were measured according to the protocol of assay kit. The prepared supernatant of the hippocampus and cortex was reacted with thiol agents to form trinitrobenzene at $37^{\circ} \mathrm{C}$; then the reaction mixture was detected at $412 \mathrm{~nm}$. AChE activity was expressed as $\mathrm{U}$ per $\mathrm{mg}$ of protein.

2.8. Western Blotting. Total proteins from hippocampus were isolated according to the instructions of the protein extraction kit. Briefly, the hippocampus was homogenized in icecold lysis buffer and then centrifuged for supernatant collection. The protein concentration was determined using a BCA protein assay kit. Protein lysates were separated by SDS-PAGE and transferred onto polyvinylidene difluoride (PVDF) membranes (Millipore Company, USA). After blocking in 5\% nonfat dry milk-Tris buffered saline with Tween-20 (TBST) for 3 hours, the membranes were incubated overnight at $4^{\circ} \mathrm{C}$ with corresponding primary antibodies, including anti-HO-1 (1:1000), anti-Nrf2 (1:1000), anti-CaMKII (1:1000), anti-pCaMKII $(1: 1000)$ anti-BDNF $(1: 1000)$, anti-TrkB $(1: 1000)$, and anti- $\beta$-actin (1:5000). After rinsing three times with TBST, membranes were incubated with a HRP-conjugated secondary antibody for $2 \mathrm{~h}$ at room temperature. Following postsecondary washes, the protein bands were visualized using an enhanced chemiluminescence (ECL) kit; then their intensities were scanned and analyzed with a Quantity One Software (Bio-Rad, Hercules, USA). 
TABLE 1: Chemical compositions of Lavandula angustifolia essential oil.

\begin{tabular}{lccc}
\hline $\begin{array}{l}\text { Peak } \\
\text { number }\end{array}$ & $\begin{array}{c}\text { Name of the } \\
\text { constituents }\end{array}$ & $\begin{array}{c}\text { Retention time } \\
(\mathrm{min})\end{array}$ & Area (\%) \\
\hline 1 & $\beta$-Pinene & 7.88 & 0.14 \\
2 & Propionic acid & 8.1 & 0.77 \\
3 & 1-Octyl-3-alcohol & 8.87 & 0.28 \\
4 & Ethyl acetate & 9.31 & 0.32 \\
5 & D-Limonene & 9.92 & 0.31 \\
6 & Eucalyptol & 10.08 & 1.22 \\
7 & trans- $\beta$-Ocimene & 10.34 & 8.6 \\
8 & 3-Carene & 10.86 & 0.79 \\
9 & cis-Linaloloxide & 12.1 & 0.12 \\
10 & Linalool & 13.89 & 37.96 \\
11 & 1-Octyl-3-alcohol & 14.35 & 0.49 \\
12 & acetate & 16.64 & 0.13 \\
13 & $(+)-2-$-Bornanone & 17.66 & 1.45 \\
14 & ( \pm -Lavandulol & 18.16 & 0.56 \\
15 & (+)-Borneol & 18.63 & 3.54 \\
16 & Terpinen-4-ol & 19.69 & 0.82 \\
17 & $\alpha$-Terpineol & 22.95 & 29.34 \\
18 & Linalyl acetate & 25.21 & 2.68 \\
19 & Lavandulyl acetate & 34.84 & 1.1 \\
20 & Caryophyllene & 38.18 & 0.69 \\
\hline
\end{tabular}

2.9. Statistical Analysis. Data were analyzed using the SPSS 17.0 software package (Chicago, IL, USA) and expressed as means \pm standard error mean (SEM). Group differences in escape latency and escape rate during acquisition of MWM trials were analyzed using repeated-measure two-way ANOVA. The other data were analyzed by one-way ANOVA followed by Tukey's post hoc test to detect intergroup differences. The results of statistical analysis were performed with GraphPad Prism software 5.0 (GraphPad Software, CA, USA). $P \leq 0.05$ was regarded as significant.

\section{Results}

3.1. Identification of LO Constituents. The chemical analysis of the lavender oil identified 31 constituents, and the following 20 constituents showed in Table 1 presented $91.31 \%$ of total LO composition. The main components of LO were linalool (37.96\%) and linalyl acetate (29.34\%), both of which accounted for $70 \%$ closely. The following were trans- $\beta$-Ocimene (8.6\%), Terpinen-4-ol (3.54\%), lavandulyl acetate $(2.68 \%),( \pm)$-Lavandulol (1.45\%), eucalyptol (1.22\%), and caryophyllene (1.1\%). Some other components were also traced in LO.

3.2. Effect of LO and LI on Open-Field Test. The locomotor activity was evaluated by open-field test. As shown in Figure 2, there were no significant changes in total distance amongst all groups, though $\mathrm{LO}+\mathrm{AD}(100 \mathrm{mg} / \mathrm{kg})$ group

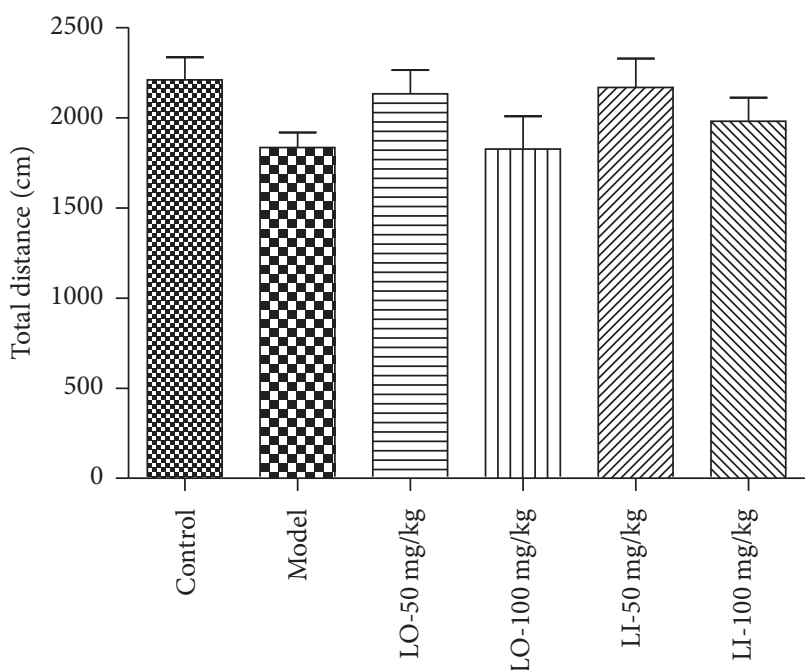

FIGURE 2: Effect of LO and LI on the total distance travelled in openfield test. Data are expressed as means \pm SEM. $n=12-13$ in each group.

and model group exhibited shorter total distance. The results excluded the influence of locomotor activity change on the evaluation of cognitive function.

3.3. Effect of LO and LI on MWM Test. In the navigation task, the cognitive performance was indicated by escape latency (Figure 3(a)) and escape rate (Figure 3(b)). Analysis of escape latency revealed significant difference between training days $(F=36.315, P<0.01)$ and between groups $(F=14.2, P<$ $0.01)$. Further comparison demonstrated that the D-gal and $\mathrm{AlCl}_{3}$ treated mice had a longer escape latency than control mice from the second day $(P<0.5)$; LO $(100 \mathrm{mg} / \mathrm{kg})$ or LI $(100 \mathrm{mg} / \mathrm{kg})$ treatment could significantly shorten the latency prolongation from day 2 to day $5(P<0.5)$ or from day 3 to day $5(P<0.5)$. LI $(50 \mathrm{mg} / \mathrm{kg})$ treatment also showed effect in the third day $(P<0.5)$. Meanwhile, the main effects for day and group were significant in escape rate $(F=42.18, P<$ $0.01 ; F=4.023, P<0.05)$. Subsequent comparison showed the obvious difference of escape rate between the D-gal and $\mathrm{AlCl}_{3}$ treated mice and control mice from the third day $(P<0.05)$. With the treatment of LO $(100 \mathrm{mg} / \mathrm{kg})$ or LI $(100 \mathrm{mg} / \mathrm{kg})$, the low escape rate of model mice would be elevated significantly from the third to fifth day $(P<0.05)$.

Probing trial was preformed to evaluate the memory of the platform position. As shown in Figures 3(c) and 3(d), the distance in target quadrant $(P<0.05)$ and the crossing number $(P<0.05)$ in $\mathrm{D}$-gal and $\mathrm{AlCl}_{3}$ treated mice were declined significantly compared with control group. However, the shorter distance in target quadrant in model group was reversed obviously by LI $(100 \mathrm{mg} / \mathrm{kg})(P<0.05)$, while the crossing number was increased with LO $(100 \mathrm{mg} / \mathrm{kg})$ or LI $(100 \mathrm{mg} / \mathrm{kg})$ treatment $(P<0.05)$.

3.4. Effect of LO and LI on Step-Through Test. In step-though test which could evaluate memory retention, the D-gal and $\mathrm{AlCl}_{3}$ treatment induced shorter latency into dark 


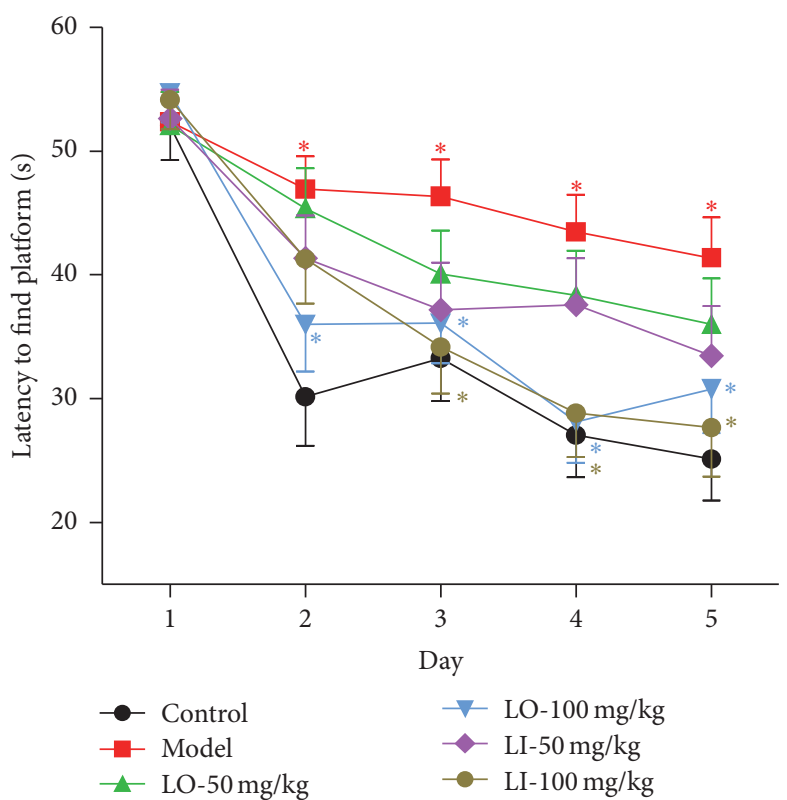

(a)

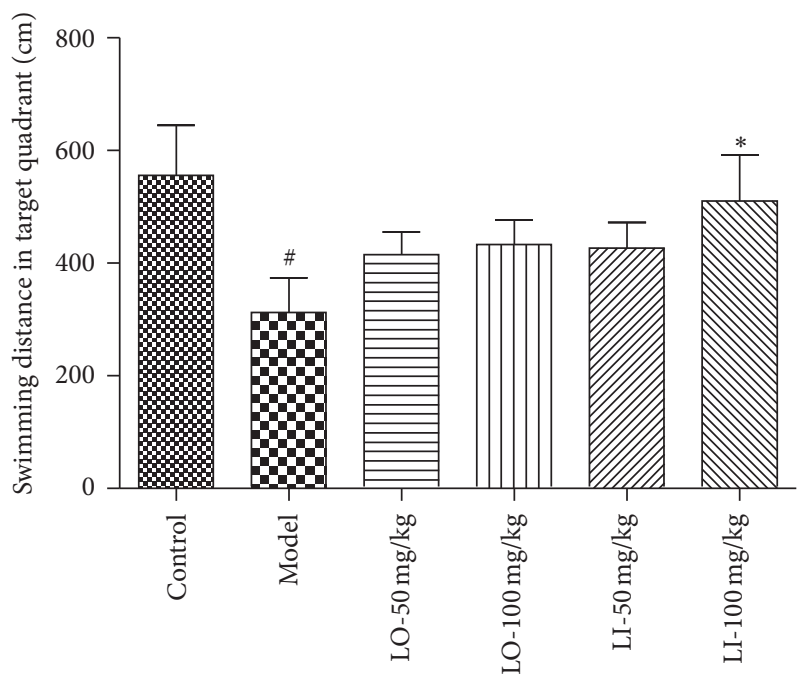

(c)

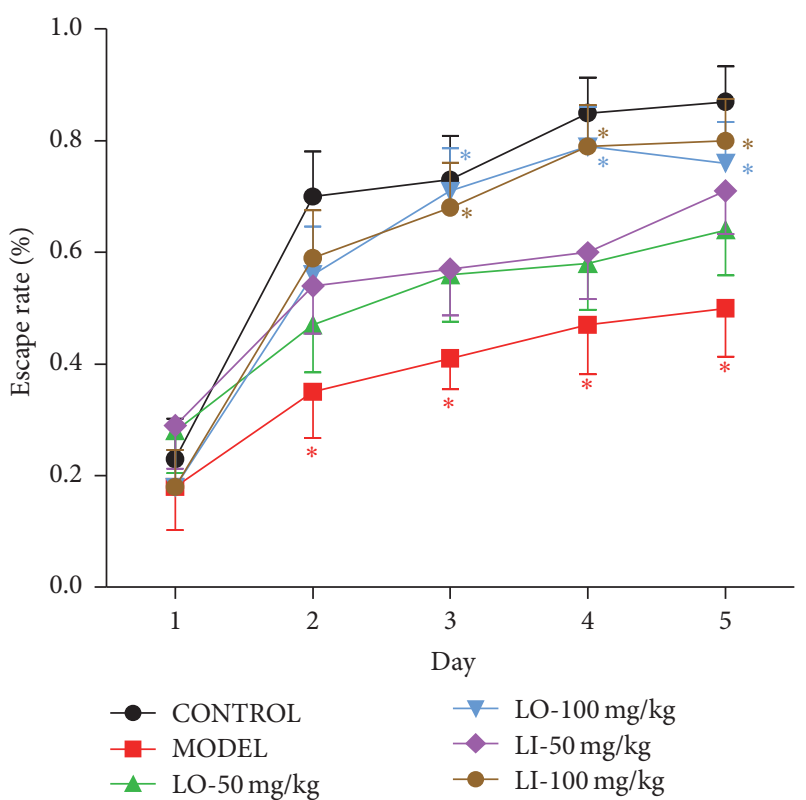

(b)

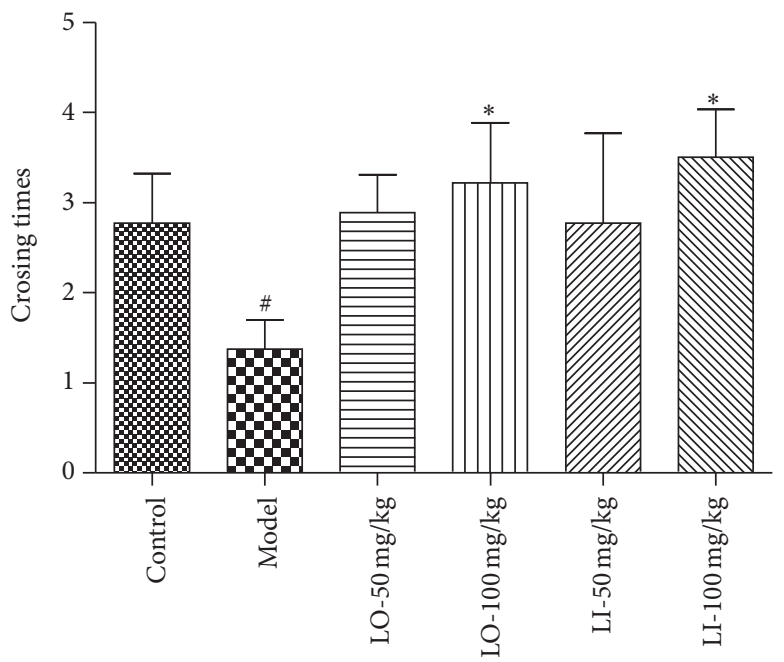

(d)

FIGURE 3: Effect of LO and LI on D-gal and $\mathrm{AlCl}_{3}$ induced cognitive deficits in MWM test. Latency to find platform (a) and escape rate (b) were measured for 5-day navigation. Swimming distance in the target quadrant (c) and crossing number (d) were recorded during the probe trial. Values are presented as mean $\pm \operatorname{SEM}\left(n=12\right.$ in each group). ${ }^{\#} P<0.05$, compared with the control group, and ${ }^{*} P<0.05$ compared with the $\mathrm{D}$-gal and $\mathrm{AlCl}_{3}$ treated group.

chamber and more error times compared with control group $(P<0.05)$. As the Figure 4 shown, LI $(100 \mathrm{mg} / \mathrm{kg})$ treatment prolonged the latency and reduced error times of model mice significantly $(P<0.05)$, while the treatment of $\mathrm{LO}$ $(100 \mathrm{mg} / \mathrm{kg})$ decreased error times close to the level of control group $(P<0.05)$.

3.5. Effect of LO and LI on Oxidative Stress Markers in the Hippocampus and the Cortex. As in Table 2, the activity of SOD and GPX was decreased significantly $(P<0.05)$ in hippocampus and cortex in groups treated with $\mathrm{D}$-gal and $\mathrm{AlCl}_{3}$, which was protected significantly $(P<0.05)$ with the treatment of
LO $(100 \mathrm{mg} / \mathrm{kg})$ or LI $(100 \mathrm{mg} / \mathrm{kg})$ except there was no significance change in the activity of GPX with the treatment of LO.

MDA is an indicator of oxidative damage, its level was significantly higher in the hippocampus of D-gal and $\mathrm{AlCl}_{3}$ treated group than control $(P<0.05$, Table 2$)$. LO $(100 \mathrm{mg} / \mathrm{kg})$ or LI $(100 \mathrm{mg} / \mathrm{kg})$ administration decreased the level of MDA significantly in hippocampus as compared to AD mice $(P<0.05)$. However, MDA levels in the cortex showed no difference amongst all groups, though there was an increase tendency of model group compared with the control. 


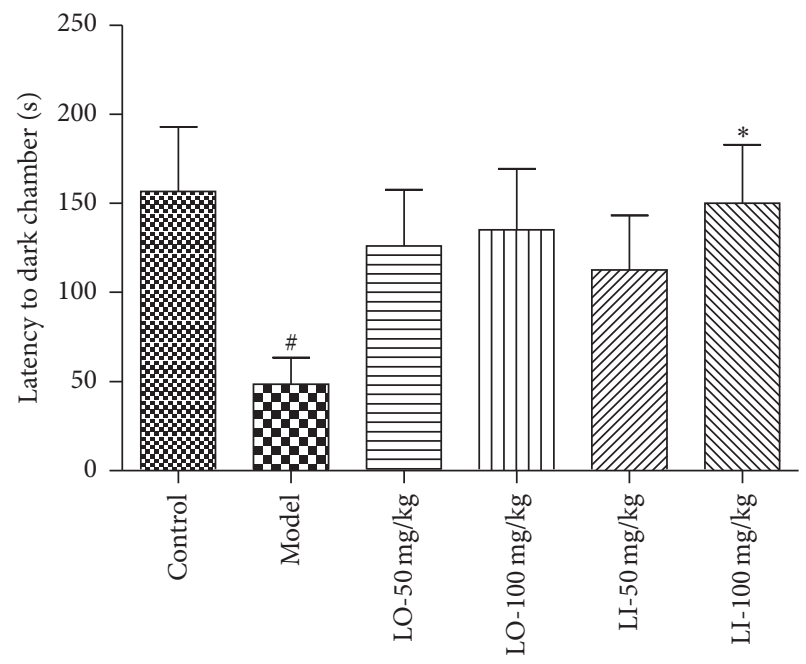

(a)

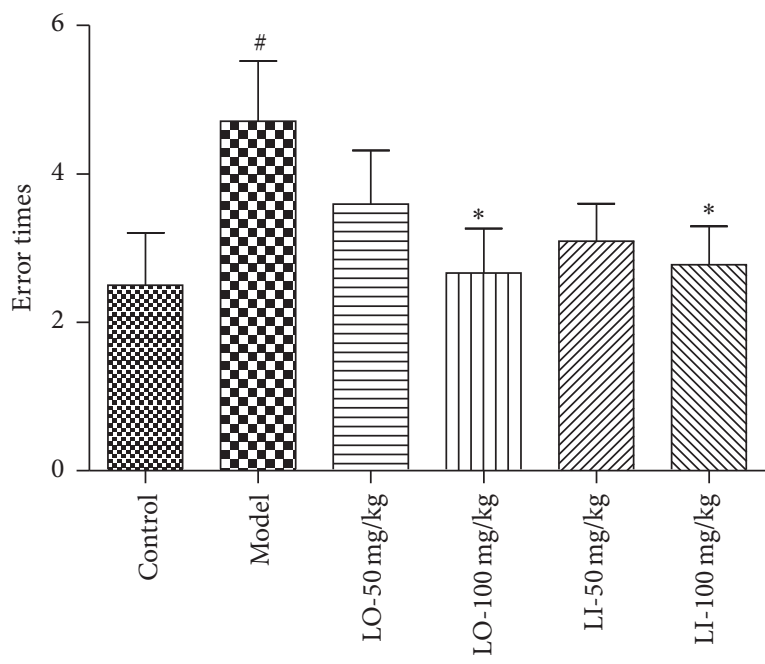

(b)

FiguRE 4: Effect of $\mathrm{LO}$ and $\mathrm{LI}$ on D-gal and $\mathrm{AlCl}_{3}$ induced cognitive deficit in step-through tests. Latency into dark chamber (a) and error times (b) were detected in consolidation trial. Data are shown as mean \pm SEM ( $n=12$ in each group). ${ }^{*} P<0.05$ compared with the control group and ${ }^{*} P<0.05$ compared with the $\mathrm{D}$-gal and $\mathrm{AlCl}_{3}$ treated group.

TABLE 2: Effects of LO and LI on the activities of SOD, GPX, and AChE and the content of MDA in the hippocampus and cortex of D-gal and $\mathrm{AlCl}_{3}$ treated mice. Values are expressed as mean \pm SEM $\left(n=10-12\right.$ in each group). ${ }^{\#} P<0.05,{ }^{\# \#} P<0.01$ compared with control group, and ${ }^{*} P<0.05$ compared with AD group.

\begin{tabular}{llcccc}
\hline Groups & & SOD & GPX & MDA & AChE \\
\hline \multirow{2}{*}{ Control } & Hip & $201.64 \pm 16.24$ & $129.42 \pm 8.39$ & $79.20 \pm 6.07$ & $91.81 \pm 0.26 \pm 1.93$ \\
& Cort & $308.21 \pm 45.21$ & $181.14 \pm 9.39$ & $9.33 \pm 0.45$ \\
Model & Hip & $161.98 \pm 24.20^{\#}$ & $98.86 \pm 9.54^{\#}$ & $100.40 \pm 6.05^{\#}$ & $9.42 \pm 0.32^{\# \#}$ \\
& Cort & $204.65 \pm 26.11^{\#}$ & $127.44 \pm 15.56^{\#}$ & $111.54 \pm 5.64$ & $9.21 \pm 0.37^{\#}$ \\
LO-50 mg/kg & Hip & $173.67 \pm 29.06$ & $114.88 \pm 12.13$ & $91.82 \pm 7.70$ & $9.06 \pm 1.03$ \\
& Cort & $228.07 \pm 36.26$ & $136.03 \pm 19.86$ & $105.02 \pm 3.66$ & $8.75 \pm 0.23$ \\
LO-100 mg/kg & Hip & $190.99 \pm 12.67^{*}$ & $127.87 \pm 4.57^{*}$ & $82.67 \pm 6.59^{*}$ & $8.06 \pm 0.20$ \\
& Cort & $292.86 \pm 50.65^{*}$ & $166.97 \pm 6.54$ & $98.33 \pm 7.30$ & $7.53 \pm 0.59^{*}$ \\
LI-50 mg/kg & Hip & $182.94 \pm 11.76$ & $109.61 \pm 4.44$ & $92.47 \pm 4.77$ & $8.85 \pm 0.24$ \\
& Cort & $270.18 \pm 40.31$ & $147.65 \pm 14.32$ & $101.35 \pm 8.65$ & $8.95 \pm 0.62$ \\
LI-100 mg/kg & Hip & $197.27 \pm 7.46^{*}$ & $128.90 \pm 9.42^{*}$ & $80.47 \pm 3.36^{*}$ & $7.96 \pm 0.25^{*}$ \\
& Cort & $302.52 \pm 40.75^{*}$ & $177.34 \pm 14.33^{*}$ & $93.67 \pm 15.05$ & $7.43 \pm 0.44^{*}$ \\
\hline
\end{tabular}

3.6. Effect of LO and LI on AChE Activity in the Hippocampus and the Cortex. AChE is a marker of cholinergic system dysfunction in the brain. Results in Table 2 showed that AChE activity in the hippocampus and cortex of the $\mathrm{D}$-gal and $\mathrm{AlCl}_{3}$ group was increased significantly compared with that of control group $(P<0.01, P<0.05)$. The LO $(100 \mathrm{mg} / \mathrm{kg})$ and $\mathrm{LI}(100 \mathrm{mg} / \mathrm{kg})$ protected the activity of AChE in the cortex of model mice $(P<0.05)$ markedly. Besides, LI $(100 \mathrm{mg} / \mathrm{kg})$ also significantly reversed the $\mathrm{D}$-gal and $\mathrm{AlCl}_{3}$ induced $\mathrm{AChE}$ activity increase in the hippocampus $(P<0.05)$.

3.7. Effect of LO and LI on Nrf2/HO-1 Pathway Protein. The Nrf2/HO-1 signaling pathway participates in the protection against oxidative stress. Thus we investigated the expressions of Nrf2 and HO-1 of different groups using Western blot. As shown in Figure 5, D-gal and $\mathrm{AlCl}_{3}$ caused a (50\%) decrease expression of Nrf2 and (60\%) of HO-1 as compared to the level of control group. With the treatment of LI $(100 \mathrm{mg} / \mathrm{mL})$ or LO $(100 \mathrm{mg} / \mathrm{mL})$, the decreased levels of Nrf2 and HO-1 in model mice were protected significantly $(P<0.01, P<0.05)$. Meanwhile, the lower dose of LI $(50 \mathrm{mg} / \mathrm{mL})$ increased the HO-1 expression obviously compared with model mice.

3.8. Effects of LO and LI on the Expression of Synapse PlasticityRelated Proteins in the Hippocampus. CaMKII is the key protein at the postsynaptic density necessary for synaptic plasticity. We investigated the effect of drugs on the expression of CaMKII and its phosphorylation by Western blot. Figures 6(a) and 6(b) showed that the $\mathrm{D}$-gal and $\mathrm{AlCl}_{3}$ group had lower level of CaMKII and p-CaMKII than the control $(P<0.05)$. However, we found a significant increase in CaMKII and p-CaMKII expression in LI + AD $(100 \mathrm{mg} / \mathrm{mL})$ 


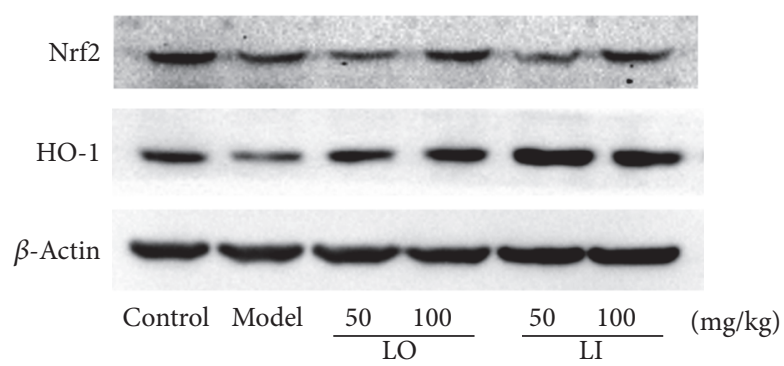

(a)

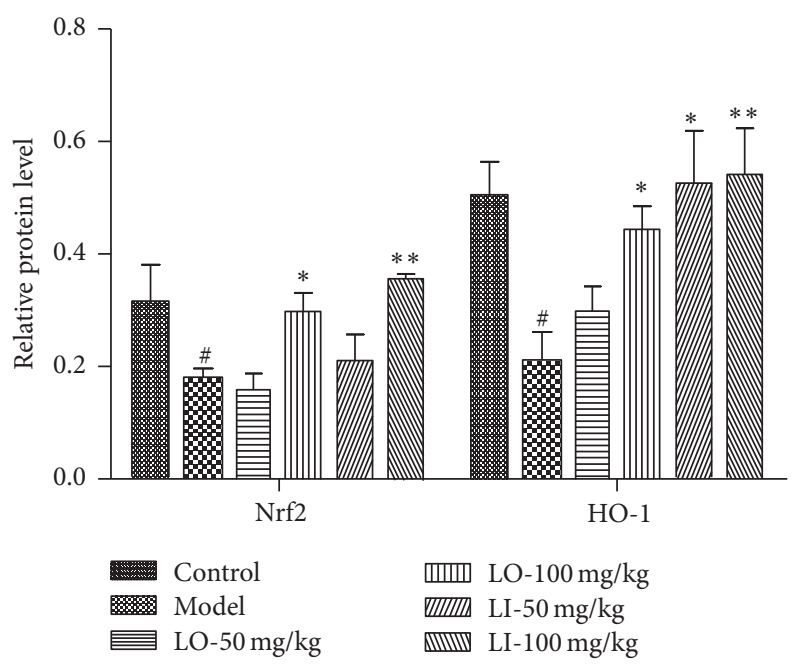

(b)

FigURE 5: Effects of LO and LI on levels of Nrf2 and HO-1 in mice hippocampus. Mice were grouped and treated as described in the text. (a) The expressions of Nrf2 and HO-1 were measured by Western blot. (b) Quantitative analysis of bands density. The ratio to $\beta$-actin was calculated ( $n=3$ per group). Values are shown as mean \pm SEM. ${ }^{\#} P<0.05$ compared with control group and ${ }^{*} P<0.05$ compared with $\mathrm{D}$-gal and $\mathrm{AlCl}_{3}$ treated group.

group as compared to $\operatorname{AD}$ group $(P<0.01, P<0.05)$. Meanwhile, those two proteins levels in model group were also reversed with the $\mathrm{LO}(100 \mathrm{mg} / \mathrm{mL})$ treatment significantly $(P<0.05)$.

BDNF, which binds to $\operatorname{TrkB}$, has multiple and distinct functions in synaptic plasticity in brain [30]. The BDNF and TrkB expressions were evaluated and showed in Figures 6(c) and 6(d). Significant lower expression of BDNF and TrkB was observed in the hippocampus of $\mathrm{D}$-gal and $\mathrm{AlCl}_{3}$ treated group when compared with the control $(P<0.05)$. Mice treated with LI $(100 \mathrm{mg} / \mathrm{mL})$ or LO $(100 \mathrm{mg} / \mathrm{mL})$ exhibited a significant increase in the expression of these proteins $(P<0.05)$.

\section{Discussion}

$\mathrm{AD}$ is a neurodegenerative disease and its prevalence is rising. The majority of $\mathrm{AD}$ cases are onset after the age of 65, accounting for more than $95 \%$ of the affected. D-gal is a reducing sugar in animals [31] which could be oxidized into hydrogen peroxide $\left(\mathrm{H}_{2} \mathrm{O}_{2}\right)$ and aldehydes when intracellular level of D-gal was excess [32]. Long-term administration of D-gal induces behavioral and neurobiological changes similar to natural aging [33]. Aluminum owns neurotoxicity, which accelerates the pathogenic course of $\mathrm{AD}$ [34]. It was reported that $\mathrm{D}$-gal and $\mathrm{AlCl}_{3}$ induced model mimic well the cognitive impairment and pathological changes in clinical $\mathrm{AD}$ [6]. Therefore, the $\mathrm{D}$-gal and $\mathrm{AlCl}_{3}$ combined administration is a good model for $\mathrm{AD}$ study and drug screening and was used in our study.

Lavender essential oil is a well-known mixture mostly extracted from L angustifolia. LO and its major component, linalool, have shown multiple bioactivities especially for AD diseases $[21,24]$. Since the composition of LO may be varies due to different origin, we examined the major contents of
LO using GC-MS [35]. A total of 31 major constituents of the LO were identified and LI accounted for $37.96 \%$ as the main component and was similar to previous reports $[36,37]$. Based on these results, we further investigated the cognitive effect of $\mathrm{LO}$ and $\mathrm{LI}$ in the $\mathrm{D}$-gal and $\mathrm{AlCl}_{3}$ treated mice and its related mechanism.

In the behavioral study, chronic $\mathrm{D}$-gal and $\mathrm{AlCl}_{3}$ administration led to the bad performance of mice in the Morris water maze test and step-though test, which was consistent with previous reports [38, 39]. Morris water maze tasks could reflect spatial memory ability of animal sensitively. The mice treated with LO or LI $(100 \mathrm{mg} / \mathrm{kg})$ have shown better cognitive function in navigation and probing process compared to the AD mice. Meanwhile, LO or LI $(100 \mathrm{mg} / \mathrm{kg})$ effectively reversed the $\mathrm{D}$-gal and $\mathrm{AlCl}_{3}$ induced cognitive impairments in step-though test, which reflects the ability of retaining and recalling information [40]. Considering the fact that there was no difference in locomotor activity amongst groups, it suggested that the cognitive amelioration of drugs is likely to be mnemonic in origin, rather not provoked by sensorimotor effects. It is worth noting that at the same dose the cognitive improvement effect of LI tended to be more potent than LO pharmacologically. For example, swimming distance in target quadrant exhibited significant increase with LI treatment only. At a given concentration, LI in LO is diluted by the presence of the other components. It may partly explain the lower effect potency of LO compared with LI.

Oxidative stress is a key factor in the progression of $\mathrm{AD}$, which can eventually induce cellular apoptosis in brain and cognitive damage [41]. ROS overproduction is widely observed in $\mathrm{AD}$, which can be indicated indirectly by analyzing MDA, a product of lipid peroxidation. The activation of antioxidant enzymes, such as SOD and GPX, could scavenge ROS and protect cells against oxidative damage [42]. In 


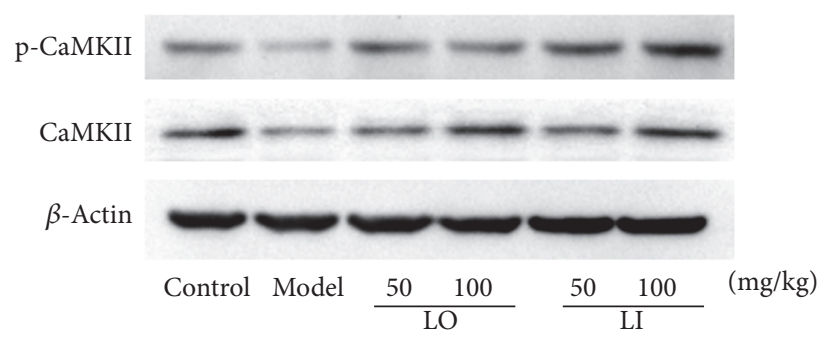

(a)

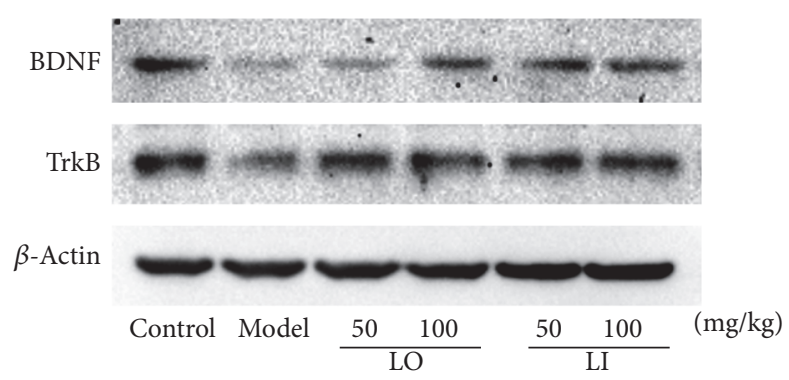

(c)

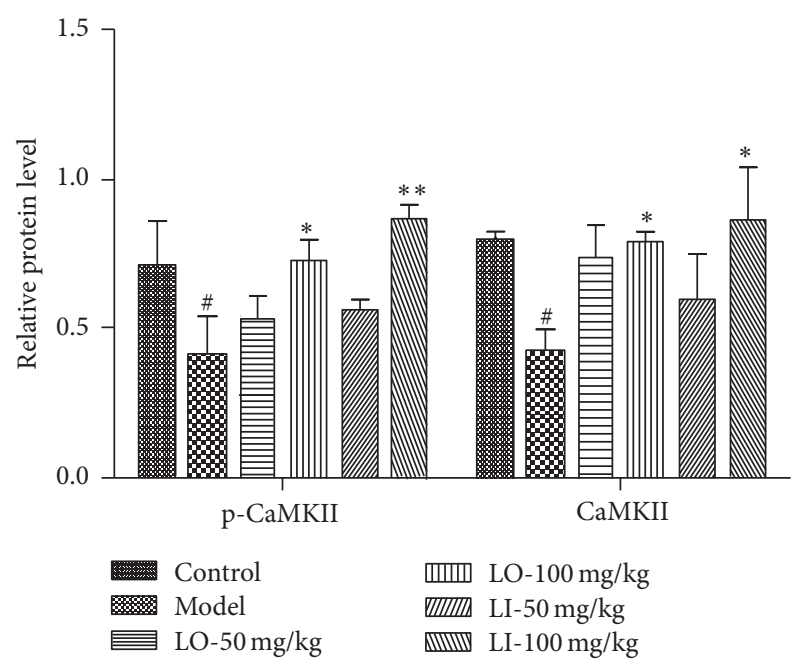

(b)

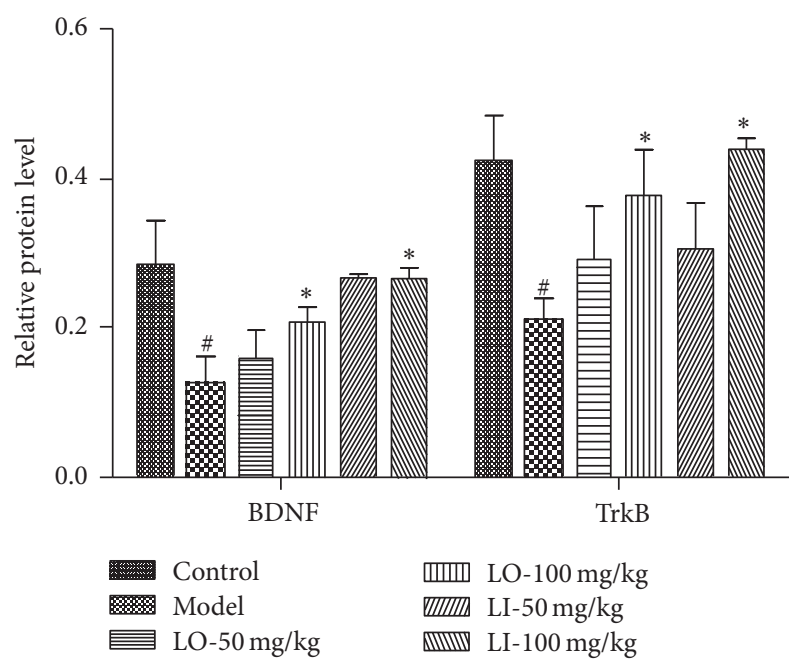

(d)

FIGURE 6: Effects of LO and LI on levels of BDNF and TrkB in mice hippocampus. Mice were grouped and treated as described in the text. The expressions of (a) CaMKII and p-CaMKII and (c) BDNF and TrkB were measured by Western blot. (b) and (d) Quantitative analysis of bands density. The ratio to $\beta$-actin was calculated ( $n=3$ per group). Values are shown as mean \pm SEM. ${ }^{\#} P<0.05$ compared with control group and ${ }^{*} \mathrm{P}<0.05$ compared with $\mathrm{D}$-gal and $\mathrm{AlCl}_{3}$ treated group.

our study, treatment with LO or LI $(100 \mathrm{mg} / \mathrm{kg})$ significantly protected the decreased activities of SOD and GPX induced by $\mathrm{D}$-gal and $\mathrm{AlCl}_{3}$ in hippocampus and elevated level of $\mathrm{MDA}$ in $\mathrm{AD}$ mice. The results indicated that $\mathrm{LO}$ and $\mathrm{LI}$ own obvious neuroprotective effect against oxidative stress, which is correlated with the previous studies [21, 43]. It is likely the mechanism underlying their cognitive enhancement effect in behavioral tests.

In the antioxidation process, Nrf2, a transcription factor, is a major protective regulator. Nrf2 could be activated and bound with antioxidant response element (ARE), then inducing the expression of defensive genes, including HO-1 [44]. HO-1 and the products of heme degradation catalyzed by HO-1 are potent and sensitive antioxidant enzymes [13]. Besides, HO-1 could induce the expression of other antioxidant enzymes, such as SOD [45]. Our results showed that the expression inhibitory of $\mathrm{HO}-1$ and $\mathrm{Nrf} 2$ induced by D-gal and $\mathrm{AlCl}_{3}$ administration was reversed markedly with LI or LO treatment. It suggested that neuroprotective effect against oxidative stress of LI or LO might be mediated by the Nrf2/HO-1 pathway.

The degeneration of cholinergic system in hippocampus and cortex is thought to be closely related to the cognitive deficits in $\mathrm{AD}$ [46]. AChE is responsible for hydrolysis of acetylcholine, which is vital for cognitive functions. Its activity is influenced by the alteration in the lipid membrane vulnerable to oxidative stress. AChE activity was increased in D-gal or aluminum treated animal brain $[6,47]$, which agreed with our result. With LO or LI treatment, the elevation of AChE activity in the hippocampus and cortex was prevented effectively, resulting in increased acetylcholine. Thus, normalization of AChE activity may be another mechanism underlying the cognitive improvement effect of $\mathrm{LO}$ and LI. 
Accumulating evidence indicated that the initial decline of memory function in $\mathrm{AD}$ is due to changes in synaptic function [48]. Synaptic plasticity underlies learning and memory progress could be elucidated by long-term potentiation (LTP) of synaptic activity well. CaMKII activity is essential for normal N-methyl-D-aspartic acid (NMDA) receptor-dependent forms of LTP and spatial learning and memory. Induced by calcium elevation, CaMKII will become its autophosphorylation form, which will be translocated to combine with $\mathrm{Ca}-\mathrm{CaM}$ complex. Their combination could regulate different postsynaptic proteins [49]. The levels of pCaMKII were observed significantly reduced in AD models [50]. BDNF, a central neurotrophic factor binding to tyrosine kinase TrkB, promotes the various neurons survival, regulates axonal and dendritic growth, and enhances synaptic plasticity in the central nervous system [51]. It was documented that BDNF protein or mRNA are significantly reduced in the brain of $\mathrm{AD}$ patients [52]. In current study, the expressions of CaMKII, p-CaMKII, BDNF, and TrkB in the hippocampus were decreased significantly in $\mathrm{D}$-gal and $\mathrm{AlCl}_{3}$ treated mice but were elevated by the treatment of LI or LO treatment effectively. The protected expression of those proteins is likely to induce the postsynaptic proteins of normal level, making sure of axonal and dendritic growth and the successful information of LTP. These results suggested that the cognitive effect of LI and LO may be partly due to its ability to enhance synaptic plasticity.

\section{Conclusion}

In summary, our study identified the composition of LO and demonstrated that LO and its main component LI significantly improved cognitive impairment induced by Dgal and $\mathrm{AlCl}_{3}$ in mice. The results indicated that these effects were related to alleviation of oxidative stress depending on Nrf2/HO-1 pathway, reversing the activity of AChE and enhancing the weakened synaptic plasticity. Taken together, it is suggested that LO, especially its main component LI, may have the potential to be developed as the drug for preventing or improving cognitive deficits in AD.

\section{Competing Interests}

Authors have no conflict of interests in this study.

\section{Acknowledgments}

This research was supported by the Xinjiang Science and Technology Aid Projects (201491174; KY2014068), the Youth Training Program of General Armament Department (2015ZZQP020), and the CAMS Initiative Project for Innovative Medicine (2016-I2M-2-006).

\section{References}

[1] T. E. Dunne, "Alzheimer's disease: an overview," in Encyclopedia of Mental Health, H. S. Friedman, Ed., pp. 58-63, Academic Press, Oxford, UK, 2nd edition, 2016.
[2] A. Stuchlik, "Dynamic learning and memory, synaptic plasticity and neurogenesis: an update," Frontiers in Behavioral Neuroscience, vol. 8, article 106, 2014.

[3] P. T. Pang and B. Lu, "Regulation of late-phase LTP and longterm memory in normal and aging hippocampus: role of secreted proteins tPA and BDNF," Ageing Research Reviews, vol. 3, no. 4, pp. 407-430, 2004.

[4] X.-M. Peng, L. Gao, S.-X. Huo, X.-M. Liu, and M. Yan, “The mechanism of memory enhancement of acteoside (verbascoside) in the senescent mouse model induced by a combination of D-gal and $\mathrm{AlCl}_{3}$," Phytotherapy Research, vol. 29, no. 8, pp. 1137-1144, 2015.

[5] Z. Li, G. Zhao, S. Qian et al., "Cerebrovascular protection of $\beta$ asarone in Alzheimer's disease rats: a behavioral, cerebral blood flow, biochemical and genic study," Journal of Ethnopharmacology, vol. 144, no. 2, pp. 305-312, 2012.

[6] F. Xiao, X.-G. Li, X.-Y. Zhang et al., "Combined administration of D-galactose and aluminium induces Alzheimerlike lesions in brain," Neuroscience Bulletin, vol. 27, no. 3, pp. 143-155, 2011.

[7] Z.-Z. Sun, Z.-B. Chen, H. Jiang, L.-L. Li, E.-G. Li, and Y. Xu, "Alteration of $\mathrm{A} \beta$ metabolism-related molecules in predementia induced by $\mathrm{AlCl}_{3}$ and d-galactose," Age, vol. 31, no. 4, pp. 277284, 2009.

[8] W. Yang, L. Shi, L. Chen et al., "Protective effects of perindopril on d-galactose and aluminum trichloride induced neurotoxicity via the apoptosis of mitochondria-mediated intrinsic pathway in the hippocampus of mice," Brain Research Bulletin, vol. 109, pp. 46-53, 2014.

[9] W.-N. Yang, X.-D. Hu, H. Han et al., "The effects of valsartan on cognitive deficits induced by aluminum trichloride and Dgalactose in mice," Neurological Research, vol. 36, no. 7, pp. 651658, 2014.

[10] Z. Cai, B. Zhao, and A. Ratka, "Oxidative stress and $\beta$-amyloid protein in Alzheimer's disease," NeuroMolecular Medicine, vol. 13, no. 4, pp. 223-250, 2011.

[11] A. E. A. Moneim, "Oxidant/antioxidant imbalance and the risk of Alzheimer's disease," Current Alzheimer Research, vol. 12, no. 4, pp. 335-349, 2015.

[12] E. Miyamoto, "Molecular mechanism of neuronal plasticity: induction and maintenance of long-term potentiation in the hippocampus," Journal of Pharmacological Sciences, vol. 100, no. 5, pp. 433-442, 2006.

[13] A. Loboda, M. Damulewicz, E. Pyza, A. Jozkowicz, and J. Dulak, "Role of Nrf2/HO-1 system in development, oxidative stress response and diseases: an evolutionarily conserved mechanism," Cellular and Molecular Life Sciences, vol. 73, no. 17, pp. 3221-3247, 2016.

[14] I. L. Ferreira, E. Ferreiro, J. Schmidt et al., "A $\beta$ and NMDAR activation cause mitochondrial dysfunction involving ER calcium release," Neurobiology of Aging, vol. 36, no. 2, pp. 680-692, 2015.

[15] J. W. Kaspar, S. K. Niture, and A. K. Jaiswal, "Nrf2:INrf2 (Keap1) signaling in oxidative stress," Free Radical Biology and Medicine, vol. 47, no. 9, pp. 1304-1309, 2009.

[16] H. M. A. Cavanagh and J. M. Wilkinson, "Biological activities of lavender essential oil," Phytotherapy Research, vol. 16, no. 4, pp. 301-308, 2002.

[17] P. H. Koulivand, M. Khaleghi Ghadiri, and A. Gorji, "Lavender and the nervous system," Evidence-based Complementary and Alternative Medicine, vol. 2013, Article ID 681304, 10 pages, 2013. 
[18] A. Vakili, S. Sharifat, M. M. Akhavan, and A. R. Bandegi, "Effect of lavender oil (Lavandula angustifolia) on cerebral edema and its possible mechanisms in an experimental model of stroke," Brain Research, vol. 1548, pp. 56-62, 2014.

[19] V. Kumar, "Characterization of anxiolytic and neuropharmacological activities of Silexan," Wiener Medizinische Wochenschrift, vol. 163, no. 3-4, pp. 89-94, 2013.

[20] M. Takahashi, A. Yoshino, A. Yamanaka et al., "Effects of inhaled lavender essential oil on stress-loaded animals: changes in anxiety-related behavior and expression levels of selected mRNAs and proteins," Natural Product Communications, vol. 7, no. 11, pp. 1539-1544, 2012.

[21] M. Hancianu, O. Cioanca, M. Mihasan, and L. Hritcu, "Neuroprotective effects of inhaled lavender oil on scopolamine-induced dementia via anti-oxidative activities in rats," Phytomedicine, vol. 20, no. 5, pp. 446-452, 2013.

[22] L. Hritcu, O. Cioanca, and M. Hancianu, "Effects of lavender oil inhalation on improving scopolamine-induced spatial memory impairment in laboratory rats," Phytomedicine, vol. 19, no. 6, pp. 529-534, 2012.

[23] C. Da Porto and D. Decorti, "Analysis of the volatile compounds of flowers and essential oils from Lavandula angustifolia cultivated in northeastern Italy by headspace solid-phase microextraction coupled to gas chromatography-mass spectrometry," Planta Medica, vol. 74, no. 2, pp. 182-187, 2008.

[24] A. M. Sabogal-Guáqueta, E. Osorio, and G. P. Cardona-Gómez, "Linalool reverses neuropathological and behavioral impairments in old triple transgenic Alzheimer's mice," Neuropharmacology, vol. 102, pp. 111-120, 2016.

[25] H. Dang, Y. Chen, X. Liu et al., "Antidepressant effects of ginseng total saponins in the forced swimming test and chronic mild stress models of depression," Progress in Neuro-Psychopharmacology and Biological Psychiatry, vol. 33, no. 8, pp. 1417-1424, 2009.

[26] R. D’Hooge and P. P. De Deyn, “Applications of the Morris water maze in the study of learning and memory," Brain Research Reviews, vol. 36, no. 1, pp. 60-90, 2001.

[27] Q. Wang, L.-H. Sun, W. Jia et al., "Comparison of ginsenosides $\mathrm{Rg} 1$ and Rb1 for their effects on improving scopolamine-induced learning and memory impairment in mice," Phytotherapy Research, vol. 24, no. 12, pp. 1748-1754, 2010.

[28] S. P. Xu, Y. Y. Yang, D. Xue et al., "Cognitive-enhancing effects of polygalasaponin hydrolysate in A $\beta 25$-35-induced Amnesic mice," Evidence-Based Complementary and Alternative Medicine, vol. 2011, Article ID 839720, 10 pages, 2011.

[29] M. Uchiyama and M. Mihara, "Determination of malonaldehyde precursor in tissues by thiobarbituric acid test," Analytical Biochemistry, vol. 86, no. 1, pp. 271-278, 1978.

[30] P. Bekinschtein, M. Cammarota, I. Izquierdo, and J. H. Medina, "Reviews: BDNF and memory formation and storage," Neuroscientist, vol. 14, no. 2, pp. 147-156, 2008.

[31] H.-M. Hsieh, W.-M. Wu, and M.-L. Hu, "Genistein attenuates $\mathrm{D}$-galactose-induced oxidative damage through decreased reactive oxygen species and $\mathrm{NF}-\kappa \mathrm{B}$ binding activity in neuronal PC12 cells," Life Sciences, vol. 88, no. 1-2, pp. 82-88, 2011.

[32] S.-C. Ho, J.-H. Liu, and R.-Y. Wu, "Establishment of the mimetic aging effect in mice caused by D-galactose," Biogerontology, vol. 4, no. 1, pp. 15-18, 2003.

[33] J. Zhu, X. Mu, J. Zeng et al., "Ginsenoside Rg1 prevents cognitive impairment and hippocampus senescence in a rat model of Dgalactose-induced aging," PLoS ONE, vol. 9, no. 6, Article ID e101291, 2014.
[34] R. R. Kaizer, M. C. Corrêa, L. R. S. Gris et al., "Effect of longterm exposure to aluminum on the acetylcholinesterase activity in the central nervous system and erythrocytes," Neurochemical Research, vol. 33, no. 11, pp. 2294-2301, 2008.

[35] C. Bicchi, L. Blumberg, C. Cagliero, C. Cordero, P. Rubiolo, and E. Liberto, "Development of fast enantioselective gaschromatographic analysis using gas-chromatographic methodtranslation software in routine essential oil analysis (lavender essential oil)," Journal of Chromatography A, vol. 1217, no. 9, pp. 1530-1536, 2010.

[36] D. L. Miladinović, B. S. Ilić, T. M. Mihajilov-Krstev, N. D. Nikolić, L. C. Miladinović, and O. G. Cvetković, "Investigation of the chemical composition-antibacterial activity relationship of essential oils by chemometric methods," Analytical and Bioanalytical Chemistry, vol. 403, no. 4, pp. 1007-1018, 2012.

[37] S. Robu, A. C. Aprotosoaie, A. Spac, O. Cioanca, M. Hancianu, and U. Stanescu, "Studies regarding chemical composition of lavender volatile oils," Revista Medico-Chirurgicala a Societatii de Medici si Naturalisti din Iasi, vol. 115, no. 2, pp. 584-589, 2011.

[38] X. Lin, S. Zhang, R. Huang et al., "Protective effect of madecassoside against cognitive impairment induced by d-galactose in mice," Pharmacology Biochemistry and Behavior, vol. 124, pp. 434-442, 2014.

[39] H. Li, T. Kang, B. Qi et al., "Neuroprotective effects of ginseng protein on PI3K/Akt signaling pathway in the hippocampus of D-galactose/AlCl3 inducing rats model of Alzheimer's disease," Journal of Ethnopharmacology, vol. 179, pp. 162-169, 2016.

[40] F. Sun, J.-D. Sun, N. Han et al., "Polygalasaponin F induces longterm potentiation in adult rat hippocampus via NMDA receptor activation," Acta Pharmacologica Sinica, vol. 33, no. 4, pp. 431437, 2012.

[41] H. Javed, M. M. Khan, A. Khan et al., "S-allyl cysteine attenuates oxidative stress associated cognitive impairment and neurodegeneration in mouse model of streptozotocin-induced experimental dementia of Alzheimer's type," Brain Research, vol. 1389, pp. 133-142, 2011.

[42] X. Zhang, A. Zhang, B. Jiang, Y. Bao, J. Wang, and L. An, "Further pharmacological evidence of the neuroprotective effect of catalpol from Rehmannia glutinosa," Phytomedicine, vol. 15, no. 6-7, pp. 484-490, 2008.

[43] S. Mehri, M. A. Meshki, and H. Hosseinzadeh, "Linalool as a neuroprotective agent against acrylamide-induced neurotoxicity in Wistar rats," Drug and Chemical Toxicology, vol. 38, no. 2, pp. 162-166, 2015.

[44] W. Li and A.-N. Kong, "Molecular mechanisms of Nrf2-mediated antioxidant response," Molecular Carcinogenesis, vol. 48, no. 2, pp. 91-104, 2009.

[45] S. Turkseven, A. Kruger, C. J. Mingone et al., "Antioxidant mechanism of heme oxygenase- 1 involves an increase in superoxide dismutase and catalase in experimental diabetes," American Journal of Physiology-Heart and Circulatory Physiology, vol. 289, no. 2, pp. H701-H707, 2005.

[46] J. L. Rogers and R. P. Kesner, "Cholinergic modulation of the hippocampus during encoding and retrieval," Neurobiology of Learning and Memory, vol. 80, no. 3, pp. 332-342, 2003.

[47] A. Kumar, A. Prakash, and S. Dogra, "Neuroprotective effect of carvedilol against aluminium induced toxicity: possible behavioral and biochemical alterations in rats," Pharmacological Reports, vol. 63, no. 4, pp. 915-923, 2011.

[48] S. Lesné, T. K. Ming, L. Kotilinek et al., "A specific amyloid$\beta$ protein assembly in the brain impairs memory," Nature, vol. 440, no. 7082, pp. 352-357, 2006. 
[49] S. Moyano, J. Del Río, and D. Frechilla, "Role of hippocampal CaMKII in serotonin $5-\mathrm{HT}_{1 A}$ receptor-mediated learning deficit in rats," Neuropsychopharmacology, vol. 29, no. 12, pp. 2216-2224, 2004.

[50] D.-M. Wang, Y.-J. Yang, L. Zhang, X. Zhang, F.-F. Guan, and L.F. Zhang, "Naringin enhances CaMKII activity and improves long-term memory in a mouse model of Alzheimer's disease," International Journal of Molecular Sciences, vol. 14, no. 3, pp. 5576-5586, 2013.

[51] K. Yamada and T. Nabeshima, "Brain-derived neurotrophic factor/TrkB signaling in memory processes," Journal Pharmacological Sciences, vol. 91, no. 4, pp. 267-270, 2003.

[52] J.-H. Song, J.-T. Yu, and L. Tan, "Brain-derived neurotrophic factor in Alzheimer's disease: risk, mechanisms, and therapy," Molecular Neurobiology, vol. 52, no. 3, pp. 1477-1493, 2015. 


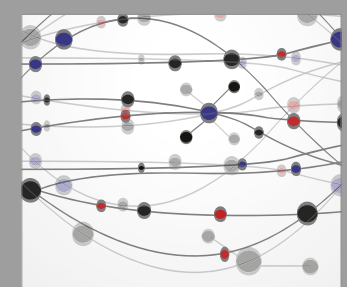

The Scientific World Journal
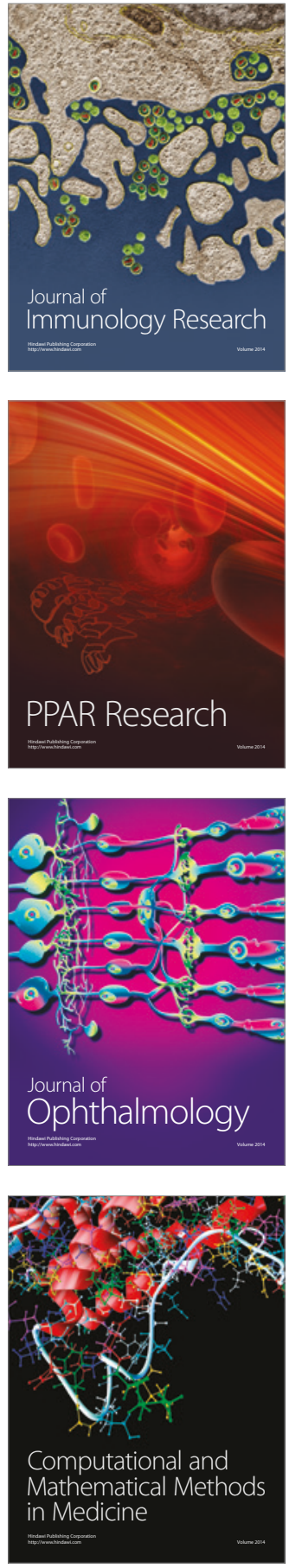

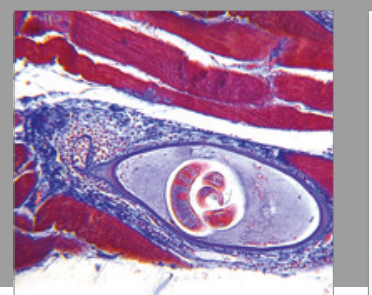

Gastroenterology Research and Practice
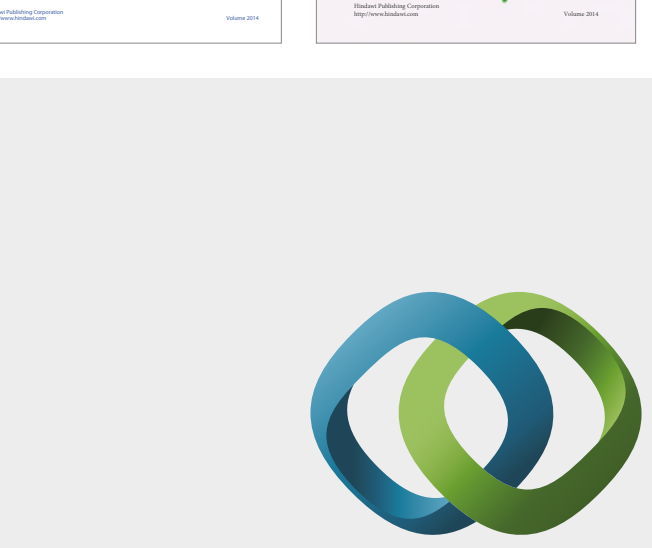

\section{Hindawi}

Submit your manuscripts at

https://www.hindawi.com
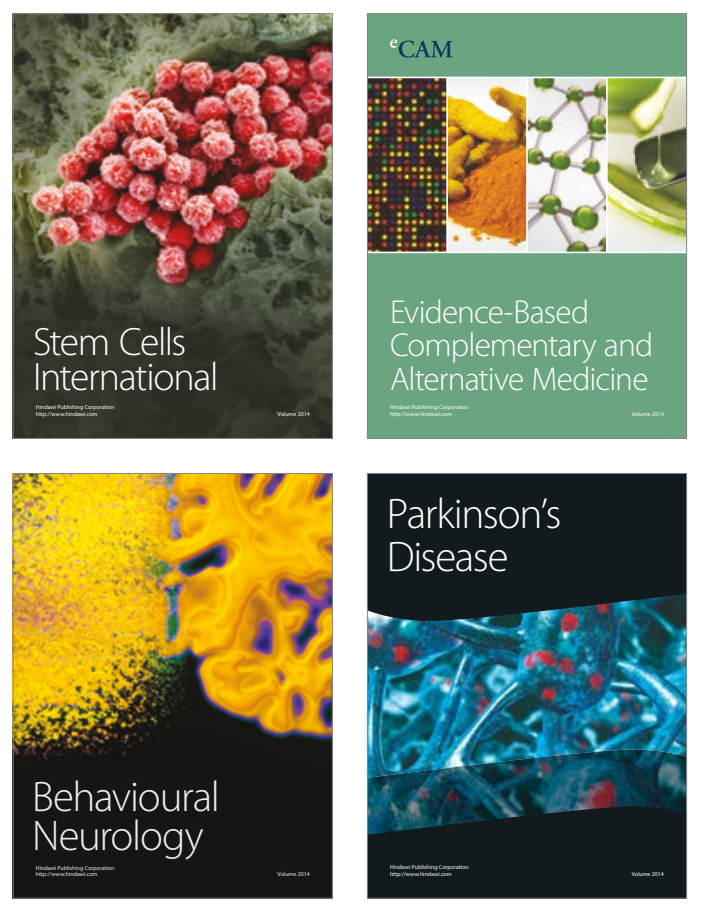
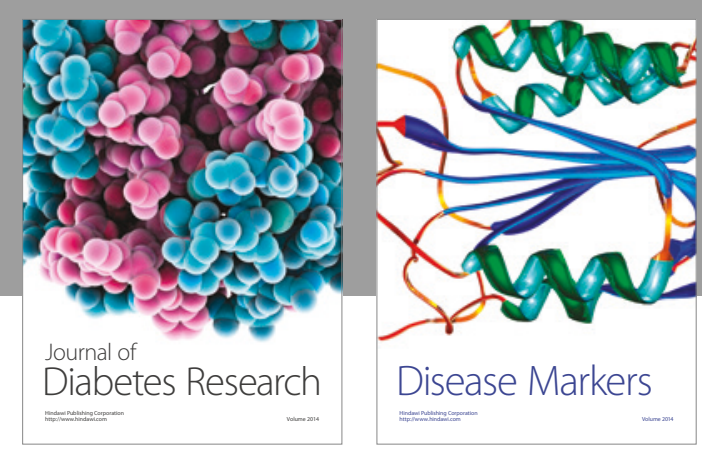

Disease Markers
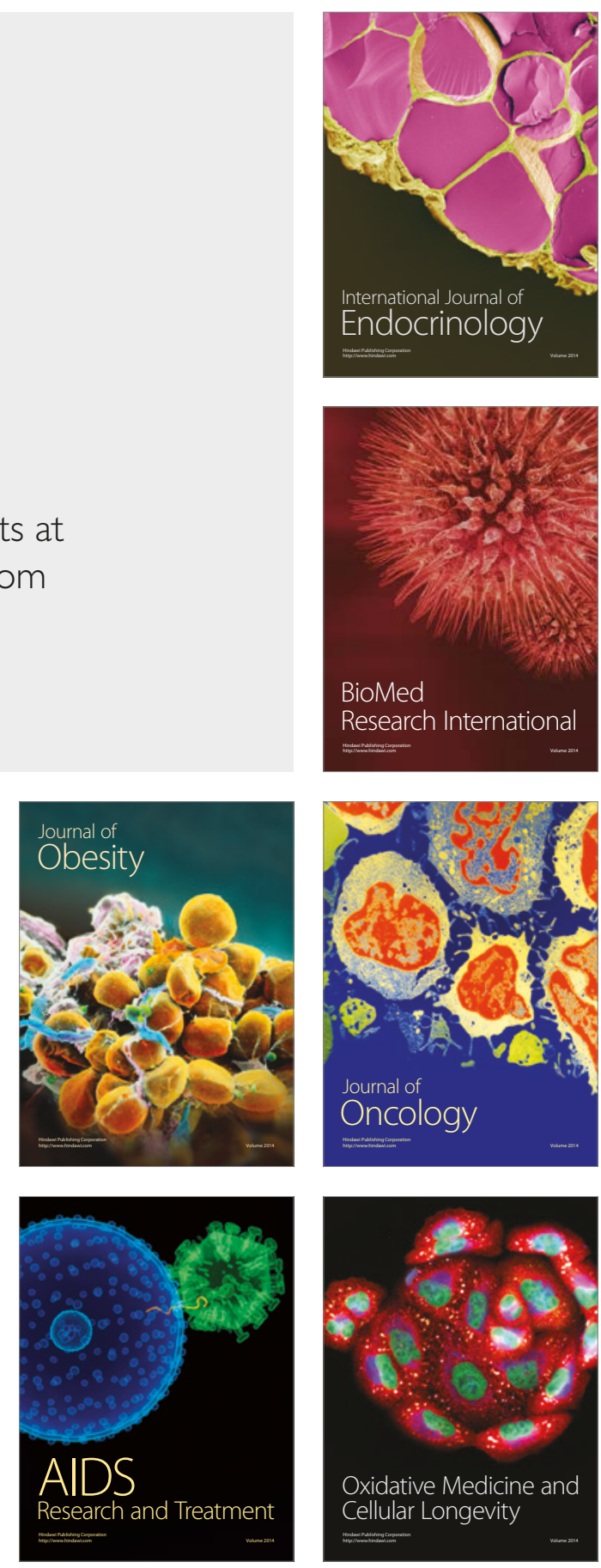